University of Nebraska - Lincoln

DigitalCommons@University of Nebraska - Lincoln

Stephen Ducharme Publications

Research Papers in Physics and Astronomy

August 1990

\title{
Intracavity frequency doubling of a Nd:YAG laser with an organic nonlinear optical crystal
}

\author{
Stephen Ducharme \\ University of Nebraska - Lincoln, sducharme1@unl.edu \\ W.P. Risk \\ IBM Almaden Research Center, San Jose, California \\ W.E. Moerner \\ IBM Almaden Research Center, San Jose, California \\ Victor Y. Lee \\ IBM Almaden Research Center, San Jose, California \\ R.J. Twieg \\ IBM Almaden Research Center, San Jose, California \\ See next page for additional authors
}

Follow this and additional works at: https://digitalcommons.unl.edu/physicsducharme

Part of the Physics Commons

Ducharme, Stephen; Risk, W.P.; Moerner, W.E.; Lee, Victor Y.; Twieg, R.J.; and Bjorklund, G.C., "Intracavity frequency doubling of a Nd:YAG laser with an organic nonlinear optical crystal" (1990). Stephen Ducharme Publications. 22.

https://digitalcommons.unl.edu/physicsducharme/22

This Article is brought to you for free and open access by the Research Papers in Physics and Astronomy at DigitalCommons@University of Nebraska - Lincoln. It has been accepted for inclusion in Stephen Ducharme Publications by an authorized administrator of DigitalCommons@University of Nebraska - Lincoln. 


\section{Authors}

Stephen Ducharme, W.P. Risk, W.E. Moerner, Victor Y. Lee, R.J. Twieg, and G.C. Bjorklund 


\title{
Intracavity frequency doubling of a Nd:YAG laser with an organic nonlinear optical crystal
}

\author{
Stephen Ducharme, W.P. Risk, W. E. Moenner, Victor Y. Lee, R. J. Twieg, \\ and G. C. Biorklund \\ IBM Almaden Research Center, San Jose, California $95120-6099$
}

(Received 15 March 1990; accepted for publication 29 May 1990)

\begin{abstract}
We have demonstrated intracavity second-harmonic generation of green $532 \mathrm{~nm}$ light in a quasi-cw $1064 \mathrm{~nm}$ Nả:YAG iaser using organic nonlinear optical crystals of 4-(N,Ndimethylamino)-3-acetamidonitrobenzene (DAN) immersed in index matching fluid contained in an antirefiection-coated cuvette. This technique permits crystals to be used directly from solution growth without polishing or antireffection coating then. Up to $0.56 \mathrm{~mW}$ peak power of $532 \mathrm{~nm}$ light was generated from $2.3 \mathrm{~W}$ of intracavity $1064 \mathrm{~nm}$ peak pewer in $100 \mu \mathrm{s}$ pulses. We also report preliminary results on true $\mathrm{cw}$ intracavity harmonic generation with antireflection-coated DAN crystals.
\end{abstract}

Intracavity second-hamonic generation (SHG) and frequency mixing using inorganic nonlinear optical (NLO) crystals such as $\mathrm{KTP}$ and $\mathrm{KNbO}_{3}$ have recently been demonstrated' to be a practical means of obtaining milliwatts of $\mathrm{cw}$ blue or green laser light from infrared diode lasers and other sources. A further enhancement in the achievable conversion efficiency could in principle be obtained using organic noninear crystals such as $4-(N, N$-dimethylamino $)-3-$ acetamidonitrobenzene (DAN), ${ }^{2-5}$ and more recently, 3-methyl-4-methoxy 4'-nitrostibene (MMONS) ${ }^{6}$ which have higher phase-matched SHG igures of merit $\left(d^{2} / n^{3}\right)$ than the inorganic NLO crystals. While intracavity SHG requires very low insertion loss, placing stringent limits on crystal optical quality as well as on absorption, there has bcen signiffcant recent progress in growing high optical quality crystals such as DAN, ${ }^{7}-N-$ - $\alpha$-rethylbenzylamino)-5-nitropyridine (MPA-NP), ${ }^{7}$-methyl-4-nitroanline (MNA), ${ }^{8}$ urea, ${ }^{7}$ and N-(4-nitrophenyl)-L-prolinol (1) (NPP) ${ }^{10}$ This work reports the first successful cw intracavity SHG using an organic NLO crystai thus demonstrating that laser grade optical quality can be achieved in highly nonhinear organic crystals.

In the present work, DAN crystals with large-area (001) faces and high internal optical quality have been grown and used to generate green $532 \mathrm{~nm}$ light using phasematched SHG when placed in the cavity of a 1064 nm Nd:YAG laser (to take advantage of the high intracavity power). Surface refiection, distortion, and scattering loss have been significantly reduced by immersing the crystals in index matching fuid contained in an antirefiection-coated spectroscopic cuvette. This technique permits insertion of noninear optical crystais as grown, without polishing or anirefiection coating, directly into the cavity of a $\mathrm{cw}$ laser and is therefore an efficient means of screening many crystais.

DAN was prepared by a two step synthesis. First, 3amino-4-fuoronitrobenzene was acetylated in chloroform with acetic anhydride. Then, the resulting acetamide was reacted with dimethylamine in dimethylsulfoxide (DMSO). The yeliow DAN powder was then purified by repeated recrystallization fron solution in a mixture of ethanol and water. Additional purification was performed by column chromatography on silica gel with a mixture of ethyl acetate and hexane followed by further recrystallizations from a mixture of methylene chloride and hexane. The purity of the DAN was confirmed by high-pressure liquid chromatography.

Single crystals of DAN were grown from DMSO solvtion in a tube with excess feed material at the bottom." Thermal convection within the tube was created by maintaining the temperature at the botrom of the tube at $29^{\circ} \mathrm{C}$ while the upper portion of the tube was held at $27^{\circ} \mathrm{C}$. High quality crystals of up to $10 \times 7 \times 2 \mathrm{~mm}^{3}$ were obtained in three to four weeks. DAN belongs to the monoclinic space group $P 2$, (point group 2) ${ }^{12}$ and the crystals grown in solution have large (001) facets and are generally trapezoidal in shape with smaller $(0 \bar{O} 0)(011),(0 \bar{l})$ and (112) facets.

Loss due to the crystal surface refiections and roughness was reduced by immersing the as-grown crystals in index matching fiud. The Cargille Series A Refractive Index Fluds (a mixture of hydrogenated terphenyl and 1 -bromonapthalcne) were contained in a BK7 glass spectrosconic cuvette which was antireflection coated for $1064 \mathrm{~nm}$ on the cuter faces [Fig. 1(a)]. Total reflection loss from the two cuvette-fluid and two fuid-crystal interfaces was calculated to be $0.4 \%$ for an optimum fuid index of $n=1.615$ and less than $1.0 \%$ for $1.5<n<1.7$ at $1064 \mathrm{~nm}$. However, the refractive index fuid absorbed enough of the laser power to cause thermal blooming and convection and slowly dissolved the crystal as well. These effects worsened with higher index fluids, presumably due to the increasing concentration of the 1-bromonapthalene component. The convection was effectively elminated by placing a shutter in the cavity, as described below. Lower absorption and solvation might be obtained with another choice of index matching fluid.

Intracavity second-harmonic generation (SHG) of the $1064 \mathrm{~mm}$ line of $\mathrm{Nd}$ :YAG was achieved by type I phase matching in $\mathrm{DAN}$ for a p-polarized fundamentai beam traveling at approximately $22^{\circ}$ from the nomal to the $(00)$ facet in a plane tilred by $2^{\circ}$ from the $(0 \overline{0} 0)$ plane. The effective SHG coefficient $d$ is $27 \pm 3 \mathrm{pm} / \mathrm{V}$ and the output at 532 $\mathrm{nm}$ is polarized along the crystalline (010) axis. ${ }^{3}$ The phasematched index of refracion is $1.732 \pm 0.005$.

The end-pumped concentric Nd.YAG laser is depicted schematically in Fig. 1(b). The TEM 0 ouput of a Tisapphire laser pumped by a cw argon laser was fockised by a 60 

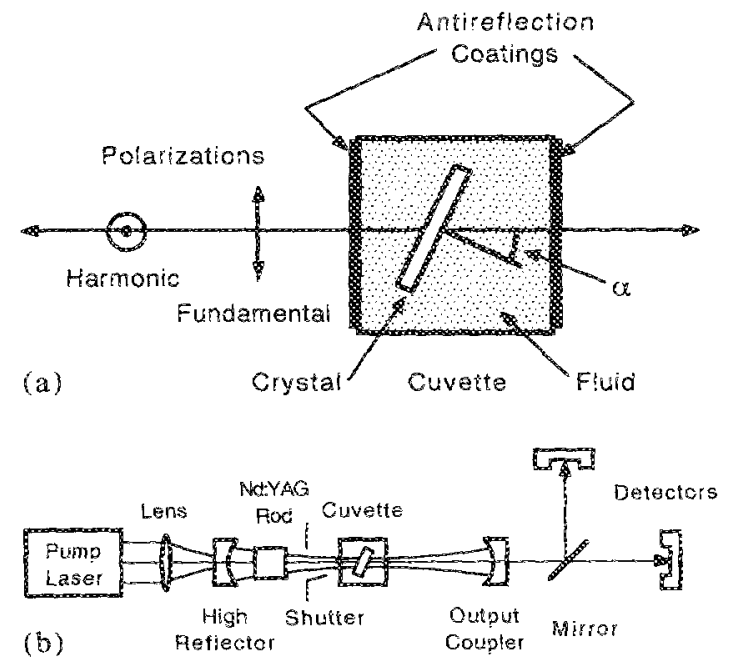

FGG. 1. (a) Diagram of the spectroscopic cuvette containing refractive index flud and the crystal oriented at the phase-matching angle $\alpha$. Both the entrance and exit fices of the cuvette are antireflection chated for $100 \%$ transmission at $1064 \mathrm{~nm}$. (b) Diagram of the end-pumped Pid: YAC laset showing the locations of the high reflector, output coupler, pump focusing lens, and the cuvette containing the DAN crystal. The dichrove miror re. fected the $1064 \mathrm{~nm}$ laser output into one detector and transmitted the 532 nm harmonic to the other detector. (Both detectors were preceded by an appropriate interference filter, not shown, to block unwanted bight.)

mm focal length lens into the $6 \mathrm{~mm}$ Nd:YAG rod located near one end of the cavity. The output coupler and high reflector were coated for 99.9 and $100.0 \%$ reflection, respectively, and the YAG laser rod was antireffection coated for $1064 \mathrm{~nm}$. The high reflector was coated for maximum transmission at the pump wavelength of $810 \mathrm{~nm}$. Both the high refector and the output coupier had radil of curvature of 75 inm and were separated by approximately $150 \mathrm{~mm}$, resulting in a near-concentric resonator configuration. The output coupler transmitted $0.1 \%$ of the incident $1064 \mathrm{~nm}$ laser power and $88.4 \%$ of the incident $532 \mathrm{~nm}$ harmonic. The fundamental and harmonic outputs of the laser were separated by a dichroic mirror and directed onto silicon photodiode derectors.

First the laser was aligned for maximum TEM $(0)$ mode output to yield approximately $2-5 \mathrm{~W}$ of $\mathrm{cw}$ intracavity power at $0.5 \mathrm{~W}$ of pump power, without the cuvete or crystal. Then the $1 \mathrm{~cm}$ path length cuvette [see Fig. $1(\mathrm{a})]$ containing the index matching fuid (but not the crystal) was inserted into the cavity with the antireflection-coated entrance and exit faces perpendicular to the cavity axis. The laser was reailgned and, when operated $\mathrm{cw}$, exhibited strong power fluctuations and poor transverse mode quality. The fiuctuations were due primarily to convection in the refractive index fuid which in turn was caused by heating of the fuid by residual absorption (less that $1 \%$ ) of the laser and pump light. To reduce fuctuations cisused by heating, a shutter was inserted between the laser rod and the cuvette [see Fig. (b)] and opened for $10 \mathrm{~ms}$ at a repetition rate of 1 to $5 \mathrm{~Hz}$. The low average power eliminated the convection, but the laser output was essentialy quenched after about $100 \mu \mathrm{s}$ by thermal blooming. Because of this, multiple pulses would often arise within the $10 \mathrm{~ms}$ shutter window and the laser could also be adjusted to yield gain-switched spikes of dura- tion less than the $20 \mu$ s rise time of the detector. The most stable ontput was obtained with a single $100 \mu$ wide pulse and a near-TEM ${ }_{00}$ spatial mode, with a peak height fluctuating between $60-80 \%$ of the empty cavity cw power, indicating that the cuvette and fuid introduced moderate linear ioss.

The DAN crystal was mounked on a six-axis stage (three translation and three rotation axes) and the crystal suspended in the fluid flled cuvette located in the cavity of the Nd:YAG laser. The laser cavity was realigned while the crystal orientation and position were adjusted to maximize both the fundamental laser output and the hamonic output. The crystal introduced a small amoune of astigmatisn and distortion into the resonator, which was clearly apparent in the shape of the output beam, as well as additional linear loss, but did not noticeably increase the thermal blooming. The peak laser cutput fiuctuated between 15 and $60 \%$ of the empty cavity ow power. Figure 2 shows the time dependence of the fundamental (lower curve) and harmonic (upper curve) outputs from the laser. Note that the second peak in the SHG output is much smaller than the second peak in the fundamental because of the quadratic dependence of the SHG on the fundamental power.

The highest SHG output was obtained with a $0.77 \cdot \mathrm{mm}$ thick crystal immersed in $n=1.624$ index fuid. With a peak intracavity Nd:YAG power (in short spikes of duration less than $10 \mu \mathrm{s}$ ) of $2.3 \mathrm{~W}$, the peak $\$$ HG power exiting one crystal face was $0.28 \mathrm{~mW}$, or $0.012 \%$ power conversion effciency. (The crystal emits the same power from the other crystal face, but this light was not collected.) The expected SHG output power from Boyd and Kieinman ${ }^{13}$ (in SF units) is $P_{2,0}=(2 \pi n L h / \lambda)\left(8 \pi^{2} d^{2} / \epsilon_{0} c \lambda^{2} n^{3}\right) \exp \left(-\alpha^{\prime} \mathcal{L}\right)\left(P_{c i}\right)^{2}$. Here, $P_{w}$ is the fundamental power, $\lambda=1064 \mathrm{~mm}, n=1.732$ is the crystal index of refraction, $L$ is the distance traversed by the beams in the crystal, $\epsilon_{0}$ is the permitivity of free space, $c$ is the speed of light, $\alpha^{\prime} \approx(1 / 2) \alpha_{2(1)} \approx 2.5 \mathrm{~cm}^{-1}$, and

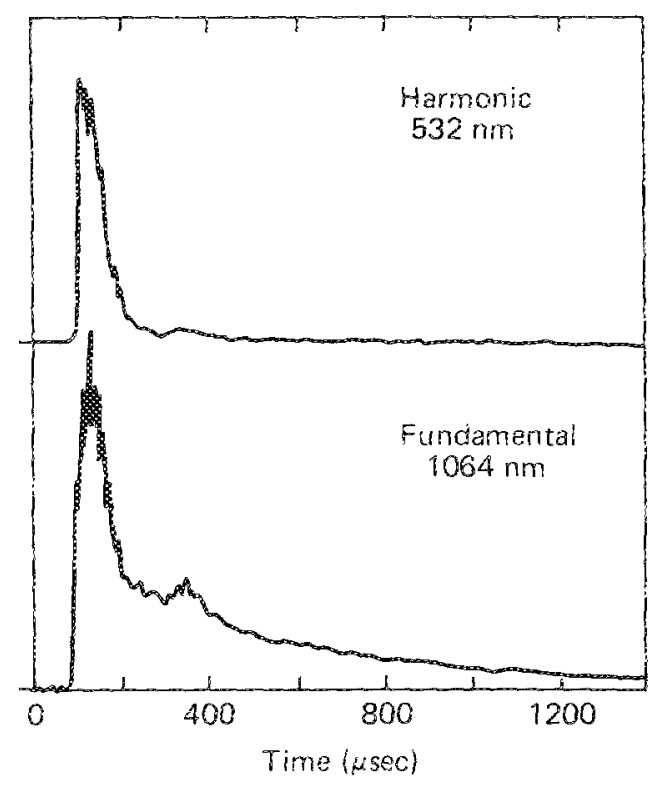

Flo. 2. Fundamental (lower curve) and second-hamonic (upper curve) ontputs from the laser. The amplitude of the initial peak of each trace was used to determine the SHG efficiency. The second smaller peak was not always present. 
$w_{0}$ is the Gaussian beam waist radius. In the limit of weak focusing ( $L \ll 2 \pi m w_{0}^{2} / \lambda$ ), but significant beam walk-of $\left(\rho L / w_{0} \geqslant 1\right), 2 \pi n L h / \lambda \approx L^{2} A(L) / \pi w_{0}^{2}$ where $\rho$ is the beam walk-of angle due to double refraction (for DAN, the walkoff angle is $\left.10.8^{\circ}\right){ }^{5}$ The value of $A(L)$ is a slow decreasing function of $\rho L / w_{0}$ and is equal to one in the absence of beam walk off. Therefore, $P_{2 w}=S\left(P_{w}\right)^{2}$ where ${ }^{13}$

$$
\begin{aligned}
S & =\left(8 \pi^{2} d^{2} / \epsilon_{0} c d^{2} n^{3}\right)\left[L^{2} A(L) / \pi w_{0}^{2}\right] \exp \left(-\alpha^{\prime} L\right) \\
& =3.7 \times 10^{-6} \mathrm{~W} / \mathrm{W}^{2} \times\left[L^{2} A(L) / \pi w_{0}^{2}\right] \exp \left(-\alpha^{2} L\right)
\end{aligned}
$$

The Gaussian beam waist in the crystal $w_{0}=70 \mu \mathrm{m}$ was determined by Gaussian mode resonator calculations (in: cluding the effect of the $Y A G$ rod) and direct measurement of the YAG ontput spot radius. For a 0.77 -mm-thick crystal at the phase-matching angle, $A(L)=0.59$, and the calculated SHG power is $0.43 \mathrm{~mW}$ which is in good agreement with the observed value $(0.28 \mathrm{~mW})$.

Figure 3 shows the $\$$ HG power exiting the crystal versus the intracavity fundamental power for a 1.3 -mm-thick crystal in $n=1.589$ index fuid. The pump power was constant at $0.5 \mathrm{~W}$ but the laser output fuctuated from pulse to pulse and each point represents the peak SHG and intraca vity powers from a single pulse. The laser output was a slightly distorted and astigmatic Gaussian TEN/ mode which also fuctuated from shot to shot. We atribute the majority of the scatter in Fig. 3 to the mode guality fuctuation which results in a fluctuation of the peak intensity of the fundamental wave at the crystal. The solid line is a least squares fit to $P_{2 \omega}=S\left(P_{\omega}\right)^{2}$ with $S=8 \times 10^{-5} \mathrm{~W} / \mathrm{W}^{2}$. The calculated value of $\$$ using $\mathrm{Eq}$. (1) [here $A(L)=0.43$ ] is $S=14 \times 10^{\cdots 5} \mathrm{~W} / \mathrm{W}^{2}$ which is in excellent agreement with the measured value.

This is the first report, to our knowledge, of intracavity hamonic generation by an organic nonlinear optical crystal. A novel technique of immersing the crystal in index matching fuid has been used which is a useful way to evaluate a new material or to aid in optimization of the growth technique. Crystals with only fair surface quality, that is with nonplanar and moderately rough surfaces, can be inserted in the cavity without polishing or antirefiection coating. We have shown that the refractive index of the fluid is not overly constrained $(1.50<n<1.70$ at 1064 nm should be suitablo

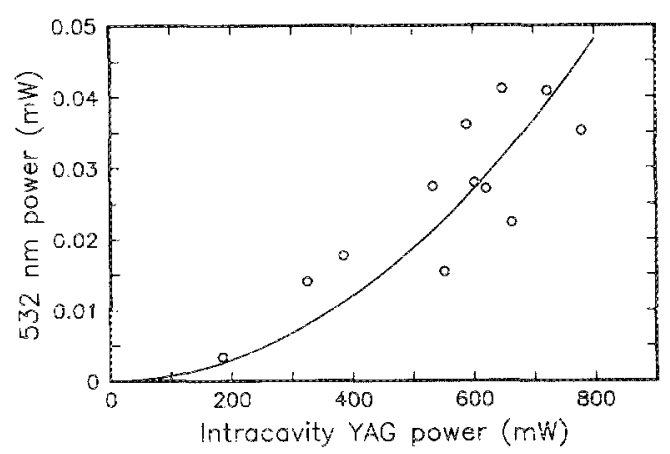

FIG. 3. The peak SHG power ys the peak fundamental intracavity power in i. 1-mm-thick crystal. The line is a least-squares fit to the relationship $P_{2 \omega}=S\left(P_{w}\right)^{2}$ with $S=8 \times 10^{-5} \mathrm{~W} / \mathrm{W}^{2}$. for DAN) but reduced absorption at the fundamental wavelength and chemical compatibility with the crystal are very important. It is likely that, with proper choice of fuid and cuvette size, stable cw intracavity $\mathrm{SHG}$ is possible. Harmonic conversion efficiencies up to $0.012 \%$ of the quasi-cw intracavity power has been achieved using this technique.

We have also recently demonstrated true cw intracavity harmonic generation using a crystal which has been polished on the (001) faces and subsequently coated for low refiection loss (0.5\% per face) in air (without the cuvette and index matching fluid). $4 \mu \mathrm{W}$ cw power (from each crystal face) of $532 \mathrm{~nm}$ light was generated from $137 \mathrm{~mW}$ of intracavity power in a 0.6-mm-thick crystal in the Nd:YAG laser described above. The output power calculated using Eq. (1) is $1.3 \mu \mathrm{W}$ assuming a beam waist radius $w_{0}=70 \mu \mathrm{m}$.

Successful laser operation and harmonic generation with an organic $\mathrm{N}$ crystal in the laser cavity is an mortant and crucial step in the quest for eficient generation of short wavelength laser light with compact laser diode sources. With its large phase-matched figure of merit and the internal quality atiained thus far, DAN is beginning to fulfil some of the early predictions of its suitability for this purpose. Although the absorption edge of DAN is at approximately $500 \mathrm{~nm}$, resonance enhancement partially compensates for absorption, producing efficient SHG for pump wavelengths as short as $970 \mathrm{rm} .^{14}$

We thank Herbert Looser for assistance and advice concerning the solution growth of the DAN crystals and W. J. Kozlowsky for useful discussions concerning the operation of the Nd:YAG laser. This work was supported in part by the U.S. Office of Naval Research.

'W. P. Risk and W. Lenth, Proc. Soc. Photo-Opt. Instrum. Engr. 1104, 13 (1989); W. P. Risk, J.C. Baumert, O. C. Bjorkiund, F. M. Schellenberg, and W. Lenth, Appl. Phys. Lett. $\mathbf{3 2}, 85$ (1988).

'R. I. Twieg and K. Jain, in Noninear Optical Properties of Organic and Polymeric Materials, edited by D.J. Williams, ACS Symp. Series No. 233

(American Chemical Society, Washington, DC, 1983), pp. 57-80; R. J. Twieg and C. W. Dirk, IBM Ressarch Report R J-5329, 1986.

'1. C. Balimert, R. J. Twieg, G. C. Rjorklund, J. A. Logan, and C. W. Dirk, Appl. Phys. I, ett. 51, 1484 (1987).

${ }^{3}$ P. A. Noman, D. Bloor, J. S. Obhi, S. A. Karaulov, M. B. Hursthouse, P. V. Kolinsky, R. J. Jones, and S. R. Hall, J. Opt. Soc. Am. B 4, 1013 $(1987)$.

P. Kerkoc, M. Zgonik, K. Sutter, Ch. Bosshard, and D. Günter, Appl. Phys. Lett. 34, 2062 (1989).

I. D. Bierlein, I. K. Chem, Y. Wang, and W. Tam, Appl. Phys. Lett. 36, 423 (1990)

'J. N. Sherwood, in Organic Materials for Nonlinear Optics, edited by D. Bloot and R. A. Itan (Royal Society of Chemistry, London, 1989), p. 71 . ${ }^{8}$ Y. Kubota and T. Yoshmum, Appl. Phys. Lett. 33,2579 (1988).

"W. R. Donakson and C. L. Tang Appl. Phys. Lett. 44, 25 (1984); G. C. Cateha, J. H. Bohn, and J. R. Luken, IEELE J. Quantum Electron. 24, 1201 (1988).

"1. I.edoxx, J. Zyss, A. Migus, J. Etchepare, G. Grillon, and A. Antonetti, Appl. Phys. Latt. 8 , 1564 (1986)

'H. Arend, R. Perret, H. Wuest, and P. Kerkoc, J. Cryst. Growh 74, 32: (1986)

12'T. C. Eluang, R. Karimi, J. C. Bamert, and G. C. Bjorklund, Eowder Diffraction $3,78(1988)$

IG. D. Boyd and D. A. Kleimman, 1. Appl. Phys. 39, 3597 (1968)

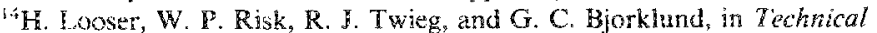
Digest. Quantum Electronics and Laser Science Conference (Optical Society of America, Washington, DC, 1989), p. 22. 